\title{
REGULAR PAPER \\ What Confucianism and for Whom? The Value and Dilemma of Invoking Confucianism in Confucian Political Theories
}

\author{
Yutang $\operatorname{Jin}^{1}$
}

Accepted: 3 September 2021

(c) The Author(s) 2021

\section{Introduction}

In his essay "why Confucius today," William de Bary $(2003,362)$ questions a quest for Confucius the original at the expense of the "problems of continuity and change" in exploring the relevance of Confucianism today. De Bary's insight brings into sharp focus how people here and now can mobilize the Confucian past in contemporary societies given that challenges of modernity have decisively shifted and displaced its social and political foundations. For many scholars, this seismic change sanctions a distinction between "Confucianism as the source of moral values" and "Confucianism as the structure of a traditional society" in a way that grounds the relevance of Confucianism in the former (Hang 2011; Smart 1998; Tu 2002; Yao 2000). This simplified dichotomy, however, blurs the moral aspect of Confucianism that seems no longer relevant (Zehou Li 1987) and the structural aspect of Confucianism that seems still relevant (Mo 2003).

Confucian political theorists have recently gone to great lengths to discuss the relevance of Confucianism to values of modernity including human rights, public reason and democracy as well as methods of inquiry. Many have explored not only compatibility between Confucianism and modernity, but also how Confucianism can contribute to normative thinking today thereby making for a wide array of theories self-identified as "Confucian" (Angle 2012; Bai 2019; Bell and Pei 2020; Chan 2013; Jenco 2017; Kim 2018; Tan 2003). These diverse accounts differ in scope and purpose and are often crosscutting rather than converse in exactly the same space. Some have a regional focus on China and East Asia while others draw on broader implications by either theorizing about Confucian methods of inquiry or directly acting on Confucian sources to engage with the wider political theory community.

Yutang Jin

yj1680@princeton.edu

1 Department of Politics, Princeton University, Princeton, NJ, USA 
Indeed, what emerges out of these diverse intellectual quests is not a unified notion of Confucian political theory, but Confucian political theories with different methodologies, audiences, conceptions of Confucianism, and their limits. ${ }^{1}$

Against this backdrop, the author discerns an urgent need to survey the changing dynamism of Confucian political theories. The rapidly mushrooming number of scholarship calls for an examination of complex ways in which Confucianism is invoked and appropriated. While almost all political theorists writing on Confucianism have some personal attachment to it, the methodological issue is especially pertinent because unlike historians and sinologists of previous decades (Levenson 1966; Munro 1969), Confucian political theorists study Confucianism not merely out of historical or geopolitical interest but as part of their normative thinking about the contemporary world. Hence, Confucian political theorists carry a unique burden of justifying their normative interest in Confucianism.

This article is not a comprehensive overview or critique of different normative positions taken by Confucian theorists. Nor is it an essentialist campaign to identify the correct approach to studying Confucianism as it does not take sides in adjudicating among different methods. Rather, the question is methodological in nature insofar as it explores whether and to what extent the value and relevance of Confucianism persists following the theorists' self-chosen methods. Recognizing the extent to which Confucianism is pliable and open to sundry methods of engagement, this article develops a taxonomy of different Confucian political theories and examines the methodological difficulties that often arise from the gap between the normative goal these theorists lay out and the way they draw on Confucianism, which was rarely attempted before. ${ }^{2}$

Despite the diversity of approaches, there is a recuring dilemma facing Confucian theorists today. Consequently, two main arguments are put forward: 1) that the potential irrelevance of Confucianism persists because of feasibility and intelligibility issues, and 2) that the two issues largely stem from a tension between finding what is genuinely valuable and distinctive in Confucianism and an attempt to renew and reconstruct Confucianism for modern times. Following recent views on feasibility in analytical philosophy, this article refers to feasibility in a unified sense of invoking accessibility and stability costs (Gilabert and Lawford-Smith 2012; Lawford-Smith 2013). Accessibility refers to how difficult it is for a community to adopt the Confucian path at a reasonable cost while stability refers to how long the chosen path of Confucianism can last if it is implemented in public state institutions. The problem of intelligibility pivots around either recognizability or redundancy depending on individual accounts. Recognizability refers to the extent to which

\footnotetext{
1 This article adopts an expansive view of Confucian political theories, which can be 1) a direct pursuit of normative Confucian visions, 2) a methodological discussion of Confucianism, or further still 3) a theory which primarily targets Confucian theorizing but nevertheless does not share Confucian normative visions.

2 Angle (2012, 10-7) and Jenco (2017) are exceptions though Angle provides preliminary mappings rather than evaluations of various streams of Confucianism and Jenco's focus is on criticizing an existing method of studying Confucianism rather than exploring internal tensions within each method. Very recently, Shaun O'Dwyer (2020) offered a critique of some of theories under examination in this article.
} 
one's identification with Confucianism is recognizably Confucian while redundancy occurs when Confucianism turns out to be not a necessary element though a theory may embody a recognizably Confucian content within its theoretical pedigree.

The rest of the article is made up of four sections. While some theorists adopt a cultural approach to examine the extent to which the state can legitimately accommodate Confucian perfectionist values, their approach begs the question of why not directly engage in the neutrality/perfectionist debate (Section II). While others attempt to either revive or reconstruct Confucianism as an intellectual contribution to the contemporary world, they lack either justification for the feasibility of Confucian revival or clear standards for reconstruction (Section III). Additionally, there are two main alternatives available that take Confucianism as neither entirely intellectual nor cultural. One can either concentrate on the fitness of Confucianism within East Asian societies or take Confucian methods of inquiry seriously and advocate for new forms of knowledge production in political theory (Section IV).

\section{The Cultural Approach and Its Problems}

The value and relevance of Confucianism often hinges on who can learn from what kind of Confucianism and in what way. The first approach can be called "culturalist." Political theorists including Sungmoon Kim, Franz Mang, and Zhuoyao Li take Confucianism to refer to a cluster of values embedded in Confucian "mores, habits, moral sentiments, and rituals" that continue to define the cultural identity of East Asians (Kim 2016, 22). ${ }^{3}$ The Confucian culture that the culturalists speak of is not a civil and learning attitude (wen) often raised in the civil/barbarian debate in East Asian history (huayi zhibian) (Jenco 2015) but a modern anthropological understanding of culture as a tradition in a relatively fixed time and space. Their primary concern is with whether and in what way it is justifiable for the state to accommodate Confucian perfectionist values that ordinary East Asians widely share in the cultural experience. Consequently, they focus on complex ways in which the state can adopt Confucian perfectionist values while respecting the "modern circumstances of social diversity, value pluralism, and moral disagreement" (Kim 2016, 3). Given that Confucian culture is territorially bound, this cultural understanding of Confucianism makes sense only within the social and geographical space of East Asia, and rarely do the culturalists attempt to draw on Confucianism to engage societies beyond it.

The cultural approach does not mean that the theorists in this group are disinterested in the genealogical study of Confucian thought. For them, however, traditional Confucian philosophy, which one can study as a historian of ideas, is no longer relevant to changing social circumstances in East Asia today (Kim 2016, 226; 2018, 51). Nor does the cultural approach imply that Confucian values cannot inform normative thinking. It does imply, however, that Confucian values are allowed to play a part in the modern state only to the extent that they facilitate and enhance the

\footnotetext{
$\overline{3}$ O'Dwyer also calls this approach culturalist.
} 
acceptance of values of modernity including "popular sovereignty, political equality, and political participation"(Kim 2016, 4).

The primary framework that the culturalists adopt for their discussion is the perfectionist/public reason approach, which closely mirrors the same kind of debate in analytical political theory. Confucian values are recast as comprehensive perfectionist values ${ }^{4}$ that promote a good way of life, and they are subsequently pitted against public reason and state neutrality. This is also where most culturalists' internal disputes arise. For Confucian perfectionists, the state should be allowed to at least partly promote some Confucian conceptions of the good (Kim 2016; Mang 2018). The neutralists, in contrast, believe that the state should keep at bay Confucian values whose role is primarily in the wider social sphere where private citizens and social communities practice Confucian virtues (Zhuoyao Li 2020). As such, Confucian perfectionism for the culturalists is not so much a source of philosophical inspiration but a morally taxing burden that contemporary East Asians need to wrestle with insofar as it is no longer morally justifiable to directly impose, as traditional societies did, perfectionist values on ordinary citizens.

The basic structure of the cultural approach can thus be set out as follows:

1. Confucianism is a cluster of values, mores, and habits closely knit together in the cultural experience.

2. To the extent that East Asians are still soaked in Confucian habits and mores, Confucian values should be taken seriously.

3. The main normative issue lies in working out ways in which Confucian perfectionist values can be legitimately promoted in the modern state.

While the way the culturalists set out the problems should be given due credit given their realistic concern over East Asian societies, their approach does raise a serious puzzle with regard to Claim 3: if Confucianism only provides a cultural context in which political philosophizing takes place and it rarely challenges and transcends values of modernity, why bother with Confucianism in the first place? Why not discuss perfectionism in general without singling out Confucian elements? It is not entirely clear, from a philosophical perspective, where the difference lies between a work on the role of Confucian perfectionism in East Asia and a work on the role of perfectionism in the modern state in general. Even if we can derive philosophical insights from engaging with the culturalists, what additional import we can gain from focusing on the Confucian context seems up in the air.

The specifics of the culturalists' debate may help to explain. Kim's theory of public reason Confucianism starts out with the dilemma of how to accommodate diversity within Confucian societies against the backdrop of value pluralism if the latter is supposed to be a major challenge to the global monism of liberal democracy. $\operatorname{Kim}(2016,80)$ then proceeds to engage with perfectionists and public reason theorists to point out that Rawls' public reason allows for pluralist interpretations in

\footnotetext{
${ }^{4}$ Confucians, however, disagree over the extent to which Confucian values are comprehensively perfectionist (Kim) or moderately and non-comprehensively perfectionist (Chan).
} 
a way that "open(s) the backdoor allowing comprehensive doctrines to sneak into the domains of public reason." Recognizing the intertwinement of public reason with comprehensive perfectionist values and the possibility of competing interpretations of public reason, Kim argues that the only non-coercive way in which differing interpretations of public reason can be resolved is through democratic participation. As a result, he claims that "public reason perfectionism is especially relevant for non-Western societies that aspire to become democratic (or more democratic) while struggling to balance new democratic institutions and practices with their nonliberal values and ways of life" (Kim 2016, 87).

It is worth noting that Kim's theory involves two layers, which can be conveniently dubbed first and second order respectively. Kim's first order theory is what he calls public reason perfectionism, which is a fusion of public reason and democratic participation that funnels perfectionist values into state politics. Kim then proceeds to claim, as a second order theory, that public reason Confucianism is a specific variant of public reason perfectionism where he finally brings in a notion of Confucianism. Confucianism in this context is nothing more than a case standing for (partial or full) comprehensive perfectionist values in the applied philosophy of his first order theory. In Kim's theory, there is no fundamental difference between Confucian perfectionist values and Catholic, Buddhist or even liberal perfectionist values except that Confucian values, as Kim claims, tacitly inform the routines of daily life in East Asia while others do not to the same degree.

Kim's interlocutors, such as Li, Mang, and Baldwin Wong, also engage in the culturalist debate in a similar fashion. ${ }^{5}$ Mang $(2019,170-71)$ believes that even Kim's democratic perfectionism disrespects democratic citizens in value plural societies because minorities including new immigrants to East Asia would never possibly reasonably agree to what comes out of a majoritarian vote on the meaning of public reason. Mang (2018), in his turn, puts forward the "wide view of moderate perfectionism" that allows citizens to appeal to comprehensive doctrines in public justifications given that their position has already been justified for widely shared, non-comprehensive reasons. Confucianism comes into play only after this basic framework of the "wide view of moderate perfectionism" is set up. Wong (2019) pushes the edge of perfectionism even further by arguing that the only legitimate role that Confucian perfectionist values can play is in the civil society, not in state institutions or policy initiatives. Li (2020, ch. 8) comes furthest down the road of public reason, arguing that the fact of value pluralism requires that a neutral state adjudicate among competing comprehensive ways of life and that there is no reason to give special treatment to Confucian values.

What seems problematic in this debate is not their problem-driven approach nor their deep appreciation of recent progress in liberal theory, but the unsettled value of grounding this debate in the Confucian context, which tends to blur the intelligibility of Confucianism and make it theoretically redundant. The confusion here largely stems from the ambiguity of the audience of the culturalists. It is utterly unclear

\footnotetext{
${ }^{5}$ One exception is Shaun O'Dwyer who shares a similar normative stance with public reason theorists but adopts a different method of what I call "fitness." More on this method later.
} 
whom the culturalists are talking to in their normative critiques. Confucianism would be at the peril of redundancy if they talk to perfectionism/public reason theorists because Confucianism is just one among many perfectionist values that play out within the public reason framework. If they are targeting those concerned with East Asia, they need to explain why and how a public reason approach addresses problems specific to the Confucian context.

On the one hand, if they are targeting liberals in the perfectionism/public reason debate-many of them have done so in a way that implies that they are proposing new theoretical breakthroughs to liberals instead of Confucians-it seems a misguided approach to carve out a field of Confucian political theory and ground their works in it taking on what they call fully comprehensive (e.g. Bai, Bell, Jiang) and moderate (e.g. Chan) Confucians. Further still, if Confucianism is no different from other comprehensive doctrines in its standing vis-à-vis public reason, why not frame the issue simply as the perfectionist dilemma in all non-Western/liberal societies? Why bother with Confucianism at all? The point is not that we cannot meaningfully bring Confucianism to bear on the public reason/perfectionism debate. Yong Huang (2015), for instance, argues that Confucianism can rectify difficulties with liberal neutrality in other-regarding actions by inducing virtuous persons voluntarily refraining from doing harm to others. The problem with the culturalists is rather that there seems nothing additional that is philosophically insightful which can be gleaned from an excursion into Confucianism. After all, if we look at Kim's, Mang's and Li's accounts, their normative insights come into force before their discussions of Confucianism begin. Given that diverse doctrines share the same nature of comprehensiveness, perhaps we can transplant the same kind of culturalist critiques to the Islamic, Catholic and Buddhist contexts, but this does not add to theoretical progress but only reproduces what is being, and supposed to be, discussed in the general debate on state perfectionism.

On the other hand, the culturalists may claim that their audience being Confucians and those interested in Confucianism is justified by Confucianism's connection to East Asia, and further by the social context of East Asia as the region that they deeply care about. What concerns them is some theorists' effort to revive and reconstruct Confucianism that violates respect for contemporary East Asians acting on increasingly plural ways of life. The culturalists, however, need, first, to do more to convince others in the field of Confucian political theory that they are serious about Confucianism as such. Currently, compared with their enthusiasm about the theories of perfectionism/public reason, they tend to mention Confucianism only in the passing by reference to an umbrella term of "Confucian perfectionist values" made up of a short list of filial piety, respect for elders, and ritual propriety. As a result, Confucianism has become a black box that serves as a convenient shortcut for the "comprehensive way of life." 6

\footnotetext{
${ }^{6}$ Kim's case is a bit more complicated as he elaborated on distinctively Confucian understandings of the self, relationality, familism, and civil society in his earlier works, but later shifted into taking up the public reason framework without thoroughly explaining how these Confucian ideas qualitatively different liberal ones can nevertheless fit into the framework of liberal origin.
} 
Second and more importantly, the culturalists' treatment of Confucianism as a case study of perfectionism may not be of particular help in resolving tensions specific to Confucianism. In order for their theory to be relevant to the Confucian context, they need to bring along their knowledge of liberal theory to go into details about what the nature of Confucian perfectionism is that differentiates it from other comprehensive doctrines, in what way it informs Confucian theory and practice, and how the problems specific to Confucian perfectionism can be addressed. Doing so will inevitably bring them to look into the complex and porous relationship between Confucian thought and culture. Insight from Chinese liberalism can be helpful. Since late Qing, Chinese liberals have long been engaging with Confucians in their normative exchanges (Ren 2004). What is distinctive of the Chinese liberal tradition is its serious engagement with the details of Confucianism-both thought and culture - and why and how it goes awry from a liberal perspective. Chinese liberal Qin Hui is a pertinent example here. As a liberal, he is deeply sympathetic to liberal values including individual freedom and the rule of law, as the culturalists do, but he discusses in detail why and how Confucianism as conventionally recognized in China is problematic. For Qin, Confucianism has played a complex role in Chinese society insofar as Confucius and Mencius inveighed against the regression of ritualistic feudal order to autocracy while mainstream Confucians after early Han transformed themselves into loyal companions of the autocratic Qin legacy. For Qin (2015), it is this Confucian culture directly traceable to Confucian thought since Han that is instrumental in hampering China's pathway to a liberal society. Again, Qin's understanding of Confucianism is not immune from criticism, but it does help to show that the culturalists need to make more efforts to discuss the specifics of Confucianism, and only by doing so can they demonstrate how their conceptual framework can help to address particular problems associated with it.

\section{The Intellectual Approach and Its Problems}

Different from the culturalists who may not necessarily identify themselves with Confucianism despite their scholastic interest in it, other contemporary theorists, who can be labelled as "intellectual," are more optimistic about the contribution of the Confucian intellectual tradition, be it understood as philosophy, classic studies, or religion. ${ }^{7}$ Apparently, they do not deny the cultural aspect of Confucianism but what matters most to them is Confucian thought emerging out of a long intellectual tradition. The value of Confucianism may seem less of a problem for these theorists given their attempt to directly tap into its theoretical insights, but again the relevance of Confucianism, as will be seen later, is not so straightforward as it looks.

\footnotetext{
7 Many Mainland Confucians do not equate Confucianism with philosophy but point to Confucian religion, commentaries and action-guiding practicality due to both the complexity of the Confucian tradition and the narrow disciplinary focus of philosophy.
} 
The "intellectual Confucians" can be further divided into two groups, revivalist and reconstructivist. The revivalists ${ }^{8}$ include Jiang Qing, Chen Ming, Kang Xiaoguang, Zeng Yi and many others, who largely belong to "Mainland Confucianism" (dalu xinrujia), a label that stands against New Confucianism in Taiwan and Hong Kong. ${ }^{9}$ I call them revivalist because they recognize the profound value of Confucianism and attempt to work out ways in which it can be revived to shape the idea of modernity suitable for East Asia, especially China. Despite internal differences, they generally agree that, in light of theoretical implications of Confucianism, China should steer a course different from the Western prototype of individual freedom and liberal democracy.

The reconstructivists, a label under which we can put Stephen Angle, Tongdong Bai, Daniel A. Bell and Joseph Chan, also focus on Confucianism as a reservoir of theoretical ideas but differ from the revivalists largely in the way in which they reconstruct Confucian philosophy to shed light on contemporary affairs. They believe that Confucian thought in its traditional form no longer makes sense for the complexity of modern societies, but nevertheless have confidence in retrieving and appropriating Confucian philosophical insights to shed light on contemporary affairs.

Despite differences between the two groups, they believe in the theoretical (not merely cultural) contribution of Confucianism in transforming the very idea of modernity. The general stance shared by revivalists and reconstructivists can be put as follows:

1. Confucianism refers to a body of thought (either philosophical or religious) sustained by a long intellectual tradition.

2. What can be retrieved from this body of thought carries normative implications for moderns.

3. These implications can, in turn, challenge the hegemony of liberal democratic universalism.

\subsection{Revivalism and Its Problems}

As shown above, the revivalists believe in reviving a chunk of traditional Confucianism as an alternative to challenge the hegemony of liberal democracy. The primary reason why the revivalists delve into Confucianism is that they believe that Confucianism can provide intellectual sources necessary for addressing pressing issues faced by China today. There is, however, as much diversity within this sub-group as there is in others. This section attends to the revivalist group by focusing on Jiang Qing, Kang Xiaoguang and Chen Ming.

\footnotetext{
${ }^{8}$ This article uses this term in a broader sense than Angle. What Angle calls revivalists and institutional Confucians can be grouped together for their faithful attitude to traditional Confucianism. For Angle's classifications, see (Angle 2012, 10-17).

${ }^{9}$ New Confucianism in Taiwan and Hong Kong formed a distinctive tradition since many intellectuals fled from China following the communist takeover.
} 
The problems they see are two-fold. First, there are serious and urgent problems in Chinese politics including the tendency to give up on "patterns of thought inherent in Chinese culture," the lack of legitimacy and pervasive injustices, and the lack of intelligible identity for sustaining the Chinese nation. Second, simply importing liberal democracy cannot but exacerbate these problems. As a result, they are as much against liberal democracy as they are for Confucianism (Chen 2014, ch. 5; Jiang 2013, 27; Kang 2005, 16-26).

In what sense does Confucianism provide solutions for the ills that they identify? Jiang and Kang advocate for restoring Confucianism as state religion. For Jiang, we need to go back to the Gongyang Commentary to the Spring and Antumn Annals in the Han dynasty to retrieve a tripartite account of Humane Authority based on the Ways of Heaven, Earth and Humans. When applied to practice, the three ways are embodied in three legislative chambers with the Way of Heaven represented by the descendants of Confucius, the Way of Earth by the meritocratic elite, and the Way of Humans by democratically elected representatives (Jiang 2013, ch. 1). Similarly, Kang's solution lies in endorsing not only the idea of non-democratic political meritocracy serving the public interest but also restoring ordinary people's faith in Confucian values (Kang 2005, ch. 5). Chen's position is more moderate than Jiang's and Kang's given that he distinguishes between religion and civil religion and only expects Confucianism's role to be the latter. Chen's ultimate interest is not in homogenizing citizens' moral and religious faith, which he deems to be infeasible, but in providing local values for "state- and nation-building" in a way that appropriates the values of democracy and constitutionalism (Chen 2014, ch. 4). If Jiang's and Kang's accounts strike a universalist tone, Chen's view is more about how modernity can be informed and sustained by a local civil religion grounded in Confucian values.

The diverse accounts of revivalism do not conceal their common patterns, which make them equally amenable to methodological critiques. With problems of China in mind, the revivalists are most unequivocal about the relevance of Confucianism, and the author is sympathetic to their insight that liberal democracy does not have ready-made solutions to many collective problems that they identify. It is, however, not clear whether Confucianism as they conceive of it is a viable option accessible to moderns and further whether the state promoting Confucian religion, civil or not, can ensure stability coming out of the longue durée. If the revival of Confucianism cannot feasibly live up to the revivalist mission, one may wonder why moderns should care about the value of Confucianism and draw on it to address the problematics that the revivalists set out. The feasibility concern especially revolves around two particular problems.

First, the China that they incline to provide a Confucian solution to is no longer the pre-modern society that hosted Confucian teachings. Even revivalists would agree that the social and political foundations that supported traditional Confucianism have rapidly vanished. The culmination of Confucian teachings since the Han dynasty with which the revivalists identify themselves was accompanied by the conditions of monarchy, the agriculture-based economy, Confucian orthodoxy in education and the civil examination system (keju). All these conditions have been displaced, if not completely dissipated, by the advent of secularism, industrialization, 
modern science and technology, the market economy, and the everyday life that people go about under modern conditions. For instance, the market economy freed individuals from the familial adage that "while your parents are alive, you should not go too far afield in your travels." The fall of metaphysical Heaven is driven by moderns' increasingly diversified spiritual and religious beliefs and their skepticism about resurrecting the idea of Heaven in the public domain (Zehou Li 1987). This is not to say that modern conditions completely block the revivalists' path toward redemption, but only that what they seek to change is far from a few tweaks to how moderns think about themselves and their relationship with the world.

Second, underlying the revivalist approach is a focus on the collective fate of China and the concomitant antipathy for ethical individualism. As Shaun O'Dwyer (2019, xi-xiv) puts it, ethical individualism posits that "the focus of ethical concern is the good of the individual." In light of Chinese women's declining suicide rate, O'Dwyer shows that the disappearance of Confucian communities in rural China turns out to be palatable from an ethical individualist perspective. One of the decisive changes that modernity ushers in is a focus on the individual as the point of departure in normative thinking. This is not to say that traditional Confucianism is collectivism of a kind that simply suppresses individual agency; nor is a rerun of the individualism-collectivism debate reminiscent of Cold War liberals pertinent in the Confucian context. Ethical individualism, however, does apply to revivalism a new set of constraints unknown to traditional Confucians in that instead of bracketing the issue of ethical individualism, they need to explain how retrieving Confucian heritage or maintaining national identity can trump concern over the agency and welfare of individuals or persons especially when the two concerns collide.

It should be noted that, compared with physical and biological law, these constraints - the modern conditions and their special variant (ethical individualism) are "soft" ones positioned on the alterable side if we think of feasibility as a matter of degree (Gilabert and Lawford-Smith 2012,813). It is surely possible to think of Confucian revival as building on a drastic transformation of modern conditions and the disappearance of the individual ethos or harmony between it and traditional Confucianism. However, the probability of the revivalists' bringing it about is not high enough, which is sufficient to undermine the revivalist approach especially when other approaches make for more accessibility and stability. This is not to discount Confucian revivalism tout court but to highlight the important feasibility questions that its proponents need to answer before setting out details of their normative proposals.

\subsection{Reconstruction and Its Problems}

While the revivalists in the intellectual approach are explicit about the relevance of the Confucian tradition, they are still prone to methodological challenges because the revivalist stance raises a range of serious feasibility questions. Partly aware of the revivalist predicament, reconstructivists within the intellectual approach largely take Confucianism as philosophy (contra commentaries or religion) and aim to reconstruct Confucian philosophy to bear on contemporary affairs. By engaging 
with the way Angle, Bai, and Chan present their arguments, I shall explain why their approach invites a different kind of methodological issues.

Despite their sharing the common ground of philosophical reconstruction, the rationales behind it are slightly different. Angle $(2012,12)$ calls his Confucian philosophy "progressive" in both senses of adopting "the core Confucian commitment to individual and collective moral progress" and promoting "progressive social change." He believes that he is doing "rooted global philosophy" (Angle 2009) given that it "means to work within a particular living philosophical living tradition - thus its rootedness - but to do so in a way that is open to stimulus and insights from other philosophical traditions - thus its global nature" (Angle 2012, 9). Similarly, Bai also works within the Confucian tradition, which makes his method also rooted. Bai $(2019,5)$ calls his method a "continuous reading" of classic Confucianism such that "we could 'ask' what Confucian and Mencius would say about democracy and human rights if they were alive today." In contrast to Angle and Bai, Chan $(2013,208)$ is explicit that he is not doing "original philosophizing within the broad framework of a philosophical tradition." Rather he compares Confucian thought with external standards and attempts to "ascertain the contemporary significance of Confucianism by placing it in the context of modern philosophy and politics and assessing it in comparison with modern viewpoints" (Chan 2013, 208). If the standards of reconstruction are internal and integral to Confucianism for Angle and Bai, they are not self-evidently so for Chan.

Distinct from the revivalists, the reconstructivists are acutely aware that it is controversial to directly appeal to traditional Confucianism to address contemporary problems where modern social conditions have taken hold. Different from the culturalists, they are clear about who their audience are-the reconstructivists are talking to not only those interested in East Asia, but more importantly to all theorists and agents beyond East Asia, and they have clearly engaged various thinkers outside the Confucian canon to justify their interest in Confucianism. In this sense, the reconstructivists differ from both culturalists and revivalists in shifting their focus from China or East Asia to global engagement. The reason they can do this shift is that they set up their accounts as Confucian philosophy, which, qua philosophy, aspires to universal engagement. ${ }^{10}$ This, however, also means that they bear more burdens of bringing Confucian philosophy into dialogue with various strands of moral and political theory outside the Confucian tradition (e.g. liberalism, republicanism, virtue ethics) insofar as they pursue an ambitious goal of making sense of Confucianism not only in societies that are traditionally and culturally Confucian, but also in the non-Confucian context where Confucian values are not widely endorsed.

Because of the extra-care the reconstructivists have taken to adapt Confucian philosophy to the modern world, their reconstructed philosophies, in normative terms, seem to be more attuned to modern conditions than those in the revivalist group. It

\footnotetext{
10 They have different understandings of the nature of Confucian philosophy. Chan denies Confucian philosophy to be organic in the sense of being malleable for radical change while Angle and Bai tend to believe that Confucian philosophy is pliable enough to accommodate new ideas while remaining intelligibly Confucian.
} 
is important here to first diffuse a potentially misleading concern about the unintelligibility of Confucianism. The puzzle can be set up as follows: 1) if Confucianism needs to adapt itself to the modern world, it must mean that it has components that are no longer suitable for the modern world. 2) The modern age is defined by distinctive social and political conditions that generate their own normative demands. 3) The relevance of Confucianism is judged by the normative demands of the modern age. 4) As a result, what is irrelevant in the reconstructed philosophy is disposed of by normative demands of the modern age and what is relevant in the reconstructed philosophy only affirms what is normatively appealing independent of Confucianism. So why should one go back to Confucianism to affirm what one already normatively desires and throw away what one already repulses? Is it a coincidence that what many reconstructivists approve of resembles what liberal democracy gets to offer (Jenco 2017)?

The problem above materializes, however, only if one accepts Premise 3 and adopts an external view of reconstructing Confucianism, which applies to one particular interpretation of Chan's method. In effect, Chan's method can be interpreted in two ways. One may interpret his idea of assessing Confucian ideals "in comparison with modern viewpoints" (Chan 2013, 208) as inviting external normative standards to judge of the contemporary relevance of Confucianism. Alternatively, one may interpret Chan's method eclectically, that is, as self-reflectively weighing up the value and ranking of Confucian and modern ideals of liberty and equality and synthesizing them in anticipation of new ideas of modernity. I call this latter way of interpretation non-trivially relevant because it not just affirms what is already accepted but proposes new ways of thinking. The redundancy of Confucianism in political theory occurs only if one adopts the external view because it only affirms what is already desirable and disposes of what is not (Confucianism in this case may still be of anthropological interest). From the way Chan (2013, 71-6) frames his Confucian philosophy in terms of service to the people, it is plain to see that he takes Confucian ideals seriously even to the exclusion of many modern values (e.g., popular sovereignty), which makes his eclectic approach verge on Angle's and Bai's approaches. After all, Angle and Bai also do not take Confucian ideals for granted but adopt them only because of their value after their comparison and engagement with values of modernity.

The methodological issue does not easily dissipate, though. The problem lies in the ambiguity of standards that one uses in renewing Confucianism and in comparing it with modern values. The idea of being "open to stimulus and insights" from others and putting oneself in a changing context does not tell much about how this context affects the way one should interpret the text. Let's take kings and hegemons in classic Confucianism for example. At one extreme, one may rebuke them altogether as tangential to Confucian thinking after being exposed to democratic values of our time. At another extreme, one may interpret kings and hegemons as showing the relevance of Confucianism as supporting enlightened autocracy and therefore the poverty of democratic values. Between them, there are also myriad arrangements that moderate and mix the two readings of Confucian rulership. It is, therefore, still unclear by what standards some textual details are taken as relevant to modern times and others are not. Partly because of this conceptual ambiguity of interpretative standards, the reconstructivists 
have drastically different understandings of what in Confucianism is still relevant today. While both adopting the idea of the elite's service to the people, Bai (2019, 34-47) interprets it as non-democratic, paternalistic rulership while Chan (2013, 90-100) understands it as being expressive of mutual trust that implies democratic election of the elite. Angle (2012, 41-57), on his part, takes the people's moral progress as essential to Confucianism and opts for active democratic participation as the locus where everyone can equally cultivate Confucian virtues.

The interpretive problem above leads to another conceptual difficulty. Careful readers are left wondering where the Confucian part of the reconstructivists' theory ends and where their modernity-informed theorizing starts. Everything normatively plausible, with few exceptions, tends to be romanticized as the "spirit" of Confucianism while those incongruent with it are cast off and treated as un-Confucian. In the end, one may ask whether some part of Confucianism is selected as relevant to us because it is more palatable to ideas of freedom, equality, and democracy, or because they defy and transcend these values. The reconstructivists draw on Confucianism because it is non-trivially relevant to modern times, but because precisely what in it is non-trivially relevant is utterly unclear (unintelligibility as unrecognizability), one may remain in doubt about the value of Confucianism in modern times. Readers may, however, take a more generous attitude toward the very uncertainty of what is valuable in Confucianism in the reconstructivist approach given that the diversity of interpretations and myriad ways in which Confucian and modern ideas can match up contribute to sundry understandings of modernity beyond a liberal democratic framework. Nevertheless, it is still incumbent on the reconstructivists to do more to show how Confucian philosophy compares with values of modernity, why the part they select is non-trivially relevant, and how they can respond to the peer critique that what they take as relevant is irrelevant or less relevant than they assume.

\section{Neither (Entirely) Cultural nor (Entirely) Intellectual: "Fitness" and Method-Centric Approaches}

The thriving field of Confucian political theories means that there exist approaches that do not neatly fit into either the culturalist or intellectual category. I discuss here two approaches that attempt to go beyond them. The first one is about "fitness" in the sense that it attempts to come up with Confucian normative ideals befitting the Confucian culture that grounds them. The second approach is the method-centric one put forward by Leigh Jenco, which focuses on the Confucian "method of inquiry." If the first approach combines cultural and intellectual approaches, the second one is neither cultural nor simply intellectual.

\subsection{The Approach of "Fitness"}

Readers may glean from the discussion thus far that one of the recurrent themes is a tension between the intelligibility of Confucianism and its feasibility. On the one hand, if one seeks little change within Confucianism (revivalism), 
Confucianism risks reducing its own relevance by being practically infeasible under modern conditions. If it seeks ambitious changes so as to adapt to modernity (reconstruction), it tends to blur its intelligibility as Confucian, which makes it unclear if one is still engaging with Confucianism as such. A different approach that attempts at reconciling the two is proposed by Confucian democrats including Roger Ames (R. Ames and Hall 1999), Henry Rosement Jr. (2015), and Sorhoon Tan (2003). These Confucians combine Confucian philosophy and culture to find guiding normative ideals for societies embedded in Confucian culture. In other words, they adopt bits of culturalism and bits of reconstruction to find a fitting Confucian philosophy for Confucian culture.

Roger Ames and David Hall's work is a quintessential example of this approach. Their goal is to explore the kind of modernity suitable for China today. They, first, start out with the distinctive cultural consciousness of China, which is defined as "the myth of Han" grounded in continuous, Confucian narratives of a specific community of people and an ongoing way (dao) (R. Ames and Hall 1999, ch. 1). This cultural basis is the testing ground for modernity-based social transformations. Second, given the multiple possibilities of modernity, the narrow focus of the dominant form of Western modernity means that "liberal, individualistic, rights-based democracy and free enterprise capitalism" are not the right kind of modernity for China (R. Ames and Hall 1999, 64; ch. 5). Third, Confucian culture therefore calls forth the kind of modernity befitting its cultural consciousness, which lies in coming up with Confucian modernity based on communitarian individuals, role ethics, and ritualized social harmony (R. Ames and Hall 1999, chs. 8-10; R.T. Ames 2010, ch. 4). For Ames and Hall (1999, chs. 6-7), this kind of modernity is made possible by affinities shared by Confucian philosophy and the pragmatic philosophy of John Dewey, who has proposed a communitarian variant of modernity ready for the Chinese to take up and amplify.

What is distinctive of Ames and Hall's work is a specific combination of cultural and intellectual (philosophical) approaches. On the one hand, they believe that the cultural genes of the community should be the starting point of normative proposals, which they take pains to identify as recognizably Confucian. On the other hand, they reject the idea of modernity simply imported from the West and propose Confucian communitarian philosophy as the guiding norms for the kind of modernity built on Confucian culture. Against this backdrop, O'Dwyer's claim that theorists like Ames and Hall are simply proposing a democracy "modified to respect...communitarian mores" (O'Dwyer 2020, 211) is too hasty a diagnosis to make sense of their approach given that the social ethos in East Asia that is only weakly communitarian does not prevent one from setting up a normative framework enhancing, or thwarting the effort to undermine, communitarian credentials. Although the particular way in which Ames and Hall identify Confucianism with Deweyan pragmatism is subject to dispute, it is clear that underlying this approach of "fitness" is an attempt to find normative ideals befitting the habits and mores from which these ideals come from. In this sense, this approach can also be called "pragmatic normativity" as it seeks to find a normative guide pragmatically built on the widely shared values of that community. 
In this light, the approach of fitness proves its uniqueness in its use of Confucianism. It keeps track of both Confucian culture and philosophy in order to find a Confucian philosophy suitable for a Confucian culture. Its uniqueness, however, also brings along specific challenges. First, although the attempt to find a fitting philosophy means that we need to get down to details of culture first and accordingly diffuse the kind of redundancy worries faced by the culturalists, one may still ask the empirical question of to what extent Chinese/East Asian cultures are still Confucian, prompting a different kind of redundancy concern. Two recent works that can be considered pertaining to "pragmatic normativity" exactly have pointed out that the social conditions in China/East Asia have changed so much so that there are no longer enough remnants of Confucian values in the public from which to build fitting normative models (Ci 2019; O’Dwyer 2019). A quest for Confucian normative models, then, may turn out to be anachronistic because there is no longer a social basis echoing it in the first place.

Secondly, fitness is a vague idea that can sanction contradictory normative guides befitting a corresponding culture. Suppose that we agree with the advocates of "fitness" that China today is still a communitarian Confucian society into which rule-centered, individualistic liberal values do not fit. We may still be unsure about whether we need a Confucian philosophy to reinforce it. On the one hand, for Confucian supporters of "fitness," the answer is yes, which is why Deweyan pragmatic democracy fits into the Chinese context much better than any alternatives. For those non-Confucian supporters of "fitness" who agree with the empirical observation of Confucian culture, however, these Confucian conditions call forth less Confucianism and more of the individualistic ethos to sway the conditions to such an extent that a new, liberal philosophy can fit in.

Although facing difficulties shared by cultural and philosophical approaches, it should also be pointed out that the method of fitness can wrestle with these difficulties better than the cultural and philosophical approaches can on their own. For instance, the empirical question does not pose as serious a challenge to the method of fitness as it does to the cultural one because that Chinese and East Asian societies are no longer thoroughly Confucian warrants not their absorption into a liberal framework but their need to be guided by a fitting Confucian philosophy. The obscurity of thresholds for interpretation faced by reconstructivists can also be addressed by the idea of fitness in that we select those Confucian philosophical ideas that fit into, and enhance, existing Confucian habits and mores widely shared among ordinary citizens. Nevertheless, the cultural and philosophical approaches are not reducible to the method of fitness in that they each have different audiences, missions, and normative assumptions.

\subsection{The Method-Centric Approach}

Jenco's Confucian account is intriguingly iconoclastic. The kind of Confucianism that she speaks of is not an anthropocentric culture of habits and mores undergirded by Confucian perfectionist values, as the culturalists believe, nor Confucian philosophy comprised of particular texts and canons, as supposed by the intellectual 
approach. Rather, Confucianism for her is intelligibly associated with a particular sense of Chineseness, or the way the Chinese adopted methods of inquiry that creatively connect past and present in acquiring and legitimating new knowledge (Jenco 2015, ch. 2). Her ultimate interest, however, is not in the content of the Confucian methods of learning per se but in the method of methods, that is, the possibilities that looking at the methods of Confucianism can open up in generating new forms of knowledge in cross-cultural engagement today.

As such, the primary interlocutors of Jenco $(2015,2)$ are comparative political theorists interested in providing "new insights into the now-global problem of how we can live with and learn from cultural others." ${ }^{11}$ For Jenco, neither universalist discourse such as liberalism premised on asymmetries of power privileging the legibility of European categories nor what she calls "particularism" which posits that each historical and sociological context constrains the possibility of engaging knowledge situated far from one's own, sanctions the genuine practice of learning from non-Western others and transforming one's own thinking. Instead, Jenco (2007) suggests new "methods of inquiry" thereby drastically transforming the way in which the West go about and enlarge the canon of political theory. For Jenco, early modern Chinese intellectuals including Yan Fu and Liang Qichao pointed to a new possibility going beyond particularism and universalism. By envisioning various ways in which new forms of knowledge from the West can be creatively connected to the Chinese past and cultural practices (wen), these intellectuals carefully attended to conditions of knowledge production and the "criteria for inclusion and exclusion in communities" that need to be negotiated and sustained in order for new knowledge to emerge and prosper (Jenco 2015, 57). In other words, the Chinese approach sanctions (radical) social change in a way that does not dismiss the context where it applies.

According to Jenco, the Chinese precedents provide profound insight into ways in which comparative political theorists can go about their own theorizing. Parallel to what Yangwu intellectuals did, ${ }^{12}$ one can reconceptualize our connection with the past by positing the "Western origin of Chinese thought" thereby collapsing the distinction between us and them (Jenco 2015, ch. 3). What seems unfamiliar in Chinese thought no longer needs to be seen as theirs alone, but as ours given the porosity of past-present connection. One can also learn from the practice of "changing referents" (bianfa) and adopt, as Tan Sitong did, the practices and institutions (qi) of other communities to aim for a total transformation of the substance (dao) of our own learning. Following the suit of Liang Qichao and Yan Fu, one can also adjust the nature and boundary of the community (qun) such that members of that community can identify themselves with new knowledge (Jenco 2015, chs. 5-6). The

\footnotetext{
11 Comparative political theory (CPT) is an emerging field of study understood as "the discursive space carved out by immanent/internal critiques of political theory's privileging of 'the West' and its marginalization of other archives." As such, it intersects with, but differs from, the field of Confucian political theory, the latter of which is the focus of the present article.

12 Yangwu or Self-Strengthening refers to a period of institutional reform from 1861 to 1895.
} 
underlying assumption here is that any possibility of new knowledge is contingent on the kinds of communities that come to define that knowledge.

Drawing on the methods that Chinese intellectuals adopted inevitably turns on her own understanding of what count as authentic methods, so her next interlocutors are Confucian political theorists especially the reconstructivists discussed above. She would certainly inveigh against the culturalists' reduction of Confucianism to a perfectionist culture fixated on a given past, but she equally charges the reconstructivists of cherry-picking and fitting Confucian sources into Western ways of thinking thereby creating a "rupture" with existing lineages of Confucian scholarship. For example, she accuses interpreters such as Joseph Chan of imputing external concepts and standards to Confucianism thereby dissociating it from its own past which makes Confucian values intelligible in the first place. Instead, Jenco (2017) enjoins theorists to turn to different, indigenous "modes of relating to the past" including the "national heritage" approach by which one seeks newness in its relationship and continuity with the past. It should be noted, however, that both comparative political theorists and reconstructivists are interested in the global scope of political theory not confined to China or East Asia. Hence, Jenco's interlocutors are actually one and the same. The only difference is that comparative political theorists theorize about, or work on, methods of political theory while Confucian reconstructivists act on these methods by bringing Confucian philosophy to directly bear on normative thinking.

Jenco's insight notwithstanding, her effort to retrieve methodological insights from Confucianism risks applying seemingly double standards to comparative and Confucian theorists. On the one hand, she urges political theorists to initiate "radical" changes by learning from what the Chinese did before and innovatively "recentering" their methods of inquiry in anticipation of genuine cross-cultural learning (Jenco 2011). On the other hand, she emphasizes the continuity of Confucian scholarship and working from within when it comes to Confucianism for contemporary societies. This two-track position may be a logical consequence of Jenco's thesis as what is radical for Western political theory presupposes the continuity of a substantially different Confucian other. This, however, leaves one wondering why Western political theory can experiment with radical changes while contemporary Confucian scholars cannot, especially given that the latter's early modern predecessors who Jenco heavily draws on tried radical and creative measures for updating Confucianism.

If we agree that these double standards are arbitrary-given that there is no reason to sanction radical change to one group and deny it to others-Jenco's suggestion will ineluctably be struck by a dilemma. The danger here is that the value of Confucianism is undermined by a difficult choice between infeasibility and redundancy. Suppose we interpret Jenco's account as suggesting that Confucian methods of inquiry entail and imply drastic changes to the way political theorists go about their theorizing. For comparative political theorists, Jenco's suggestion would lead them to radically and paradoxically infuse their accounts with the less radical methods of indigenous Confucian scholarship (otherwise there would be no radicalism for Western political theory), which in turn risks making political theory infeasible (both inaccessible and unstable) in the real world. It is precisely because the 
preexisting ways of connecting with the past stopped working in modernizing China that they were relinquished piecemeal by Confucian intellectuals. For instance, Jiang's metaphysical configurations underlying his revivalist, tripartite account of legitimacy in terms of Heaven, Earth and Humans may be more of a radical option than reconstructivist theories (e.g. Chan's) for political theorists in the West to hew to in their reshuffling of methods, but Jiang's recommended path declined because the metaphysical mode of thinking it substantiated is no longer accessible to moderns. Even if we make them accessible, how stable would a modern society in the West be following an update of theoretical methods in this way? After all, Jenco needs to explain, in addition to how the Chinese acquired new knowledge, why the methods that have been tried but either abandoned or fiercely disputed within the Confucian context are something that the West can meaningfully access and render stable. On the other side, for contemporary Confucians especially the reconstructivists, adopting radical methods, as suggested by Jenco, may be already underway. Chan invokes Confucian ideals and uses the modern institution of democracy to substantiate it in the same way that Tan draws on democratic institutions of the West to thoroughly transform the Confucian Way (or perhaps Chan is not even radical enough!). It turns out that Jenco theoretically reaffirms what the reconstructivists have already been doing.

Alternatively, Confucianism may imply, not rupture, but diverse "lines of connecting with the past" and its own "terms through which knowledge is produced" (Jenco 2015, 217). If so, first, the same feasibility concern over comparative political theory can be raised to Confucian scholarship as the path suggested by Jenco may be practically infeasible. Second, this interpretation renders the value of Confucian methods redundant for Western political theorists as they, after all, do not need to make as radical changes to their methods as otherwise is the case precisely because their priority should be adhering to their own lines of connecting to the past in the same way that Confucian theorists do.

\section{Conclusion}

Against the deeply entrenched crisis of Western modernity, drawing on the indigenous, Confucian tradition seems to be a tempting and inevitable vocation for many Confucian political theorists. As Tu Weiming $(2000,198)$ puts it, "traditions continue in modernity." In this article, I surveyed a vast array of different ways in which Confucianism is invoked to serve normative justifications and pointed out the difficulties with each of them. Underlying this increasingly diversified landscape are the theorists' different understandings of social change and the degree to which Confucianism can respond to it, which hearkens back to the age-long debate about "substance" ( $t i$ ) and "function" (yong) in Chinese intellectual history. Adopting this hermeneutical lens, one may say that the revivalists support both substance and function being Confucian, the method-centric theorists lean toward "Confucian substance and Western function," the culturalists act on an updated version of "Western substance and Confucian function," and those adopting philosophical and "fitness" approaches lie somewhere between the latter two. As Li Zehou $(1987,346)$ remarks, 
porous and shifting boundaries between substance and function are not entirely a figment of the intellectuals' imagination but a proxy for challenges of "modern society."

These challenges have displaced and constrained the boundaries of Confucian knowledge, whose universality is called into question, and this further elicited divergent Confucian-inspired responses. The use of Confucian sources can be vulnerable to the critiques of irrelevance precisely because different constraints apply depending on what kind of Confucianism one works on, whom one talks to, and in what way. As such, the risk of diminishing the value and relevance of the non-Western source like Confucianism can emerge in each layer and stage of theorizing. At the end of the day, it is the audience one targets, the problems one wants to address, and the methods and standards one adopts in approaching Confucianism that jointly determine and test its value today.

Acknowledgement I would like to especially thank Steve Angle, with whom I co-taught a course on Confucian political theory at Wesleyan University. Both the course itself and the productive conversations I had with him were a great source of inspiration. I would also like to thank Nick Bunnin for the virtual conversations we had during lockdowns in the UK, which helped to refine my ideas.

Author contribution All contributions are of my own.

Funding This publication was kindly supported by the Princeton University Library Open Access Fund.

Data Availability Data sharing not applicable to this article as no datasets were generated or analyzed during the current study.

Code Availability Endnote.

\section{Declarations}

Conflict of interest The author declares that he has no conflict of interest.

Open Access This article is licensed under a Creative Commons Attribution 4.0 International License, which permits use, sharing, adaptation, distribution and reproduction in any medium or format, as long as you give appropriate credit to the original author(s) and the source, provide a link to the Creative Commons licence, and indicate if changes were made. The images or other third party material in this article are included in the article's Creative Commons licence, unless indicated otherwise in a credit line to the material. If material is not included in the article's Creative Commons licence and your intended use is not permitted by statutory regulation or exceeds the permitted use, you will need to obtain permission directly from the copyright holder. To view a copy of this licence, visit http://creativecommons.org/licen ses/by/4.0/.

\section{References}

Ames, Roger, and David Hall. 1999. The Democracy of the Dead: Dewey, Confucius, and the Hope for Democracy in China. Chicago: Open Court.

Ames, Roger T. 2010. Confucian Role Ethics: A Vocabulary. Hong Kong: Chinese University Press.

Angle, Stephen C. 2009. Sagehood: The Contemporary Sgnificance of Neo-Confucian Philosophy. New

York: Oxford University Press.

Angle, Stephen C. 2012. Contemporary Confucian Political Philosophy. London: Polity. 
Bai, Tongdong. 2019. Against Political Equality: The Confucian Case. Princeton, NJ: Princeton University Press.

Bell, Daniel A., and Wang Pei. 2020. Just Hierarchy: Why Social Hierarchies Matter in China and the Rest of the World. Princeton: Princeton University Press.

Chan, Joseph. 2013. Confucian Perfectionism: A Political Philosophy For Modern Times. Princeton, NJ: Princeton University Press.

Chen, Ming. 2014. Confucian Religion and Civil Society. Beijing: Dongfang Press.

Ci, Jiwei. 2019. Democracy in China: The Coming Crisis. Cambridge, MA: Harvard University Press.

De Bary, William Theodore. 2003. "Why Confucius Today." In Confucianism for the Modern World, edited by Daniel A Bell and Hahm Chaibong, 361-372. Cambridge: Cambridge University Press.

Gilabert, Pablo, and Holly Lawford-Smith. 2012. Political Feasibility: A Conceptual Exploration. Political Studies 60 (4): 809-825.

Hang, Lin. 2011. Traditional Confucianism and Its Contemporary Relevance. Asian Philosophy 21 (4): $437-445$.

Huang, Yong. 2015. Confucianism and the Perfectionist Critique of the Liberal Neutrality: A Neglected Dimension. The Journal of Value Inquiry 49 (1): 181-204.

Jenco, Leigh. 2007. "What does Heaven Ever Say?" A Methods-Centered Approach to Cross-Cultural Engagement. American Political Science Review 101 (4): 741-755.

Jenco, Leigh. 2011. Recentering Political Theory: the Promise of Mobile Locality. Cultural Critique 79: 27-59.

Jenco, Leigh. 2015. Changing Referents: Learning Across Space and Time in China and the West. Oxford: Oxford University Press.

Jenco, Leigh. 2017. How Should we Use the Chinese Past? Contemporary Confucianism, the 'Reorganization of the National Heritage' and non-Western Histories of Thought in a Global Age. European Journal of Political Theory 16 (4): 450-469.

Jiang, Qing. 2013. A Confucian Constitutional Order: How China's Ancient Past Can Shape Its Political Future. Princeton, NJ: Princeton University Press.

Kang, Xiaoguang. 2005. Humane Government: A Third Road for the Development of Chinese Politics. Singapore: Global Publishing Co.

Kim, Sungmoon. 2016. Public Reason Confucianism: Democratic Perfectionism and Constitutionalism in East Asia. Cambridge: Cambridge University Press.

Kim, Sungmoon. 2018. Democracy After Virtue: Toward Pragmatic Confucian Democracy. Oxford: Oxford University Press.

Lawford-Smith, Holly. 2013. Understanding Political Feasibility. Journal of Political Philosophy 21 (3): 243-259.

Levenson, Joseph Richmond. 1966. Confucian China and Its Modern Fate. Berkeley, CA: University of California Press.

Li, Zehou. 1987. An Analysis of the History of Modern Chinese Thought. Beijing: Dongfang Publishing.

Li, Zhuoyao. 2020. Political Liberalism, Confucianism, and the Future of Democracy in East Asia. New York: Springer.

Mang, Franz. 2018. Confucianism, Perfectionism, and Liberal Society. Dao 17 (1): 29-49.

Mang, Franz. 2019. Why Public Reason Could Not Be Too Modest: The Case of Public Reason Confucianism. Journal of Social Philosophy 50 (2): 163-176.

Mo, Jongryn. 2003. "The Challenge of Accountability: Implications of the Censorate." In Confucianism for the Modern World, edited by Daniel A Bell and Hahm Chaibong. Cambridge: Cambridge University Press.

Munro, Donald. 1969. The Concept of Man in Early China. Stanford: Stanford University Press.

O’Dwyer, Shaun. 2019. Confucianism's Prospects: A Reassessment. New York: SUNY Press.

O'Dwyer, Shaun. 2020. Confucian Democrats, Not Confucian Democracy. Dao 19 (2): 209-229.

Qin, Hui. 2015. Beyond the Monarchy: From Late Qing to Early Republican History in China. Beijing: Qunyan Publishing.

Ren, Jiantao. 2004. Liberalism in Modern Chinese Thought. Beijing: Peking University Press.

Rosemont Jr, Henry. 2015. Against individualism: A Confucian Rethinking of the Foundations of Morality, Politics, Family, and Religion. Lanham: Lexington Books.

Smart, Ninian. 1998. The World's Religions. Cambridge: Cambridge University Press.

Tan, Sor-hoon. 2003. Confucian Democracy: A Deweyan Reconstruction. Albany, NY: SUNY Press.

Tu, Weiming. 2000. Implications of the Rise of 'Confucian' East Asia. Daedalus 129 (1): 195-218.

Tu, Weiming. 2002. The Collected Works of Tu Weiming, vol. III. Wuhan: Wuhan Publishing House. 
Wong, Baldwin. 2019. A Non-Sectarian Comprehensive Confucianism?-On Kim's Public Reason Confucianism. Journal of Social Philosophy 50 (2): 145-162.

Yao, Xinzhong. 2000. An Introduction to Confucianism. Cambridge: Cambridge University Press.

Publisher's Note Springer Nature remains neutral with regard to jurisdictional claims in published maps and institutional affiliations. 